\title{
Exercising in digital way: Mobile fitness application and their accuracy
}

\author{
R. R. Liyanage ${ }^{\# 1}$, D. Dhammearatchi ${ }^{* 2}$ \\ \# Department of IT, CINEC Campus \\ Millennium Drive, IT Park, Malabe, Sri Lanka \\ ${ }^{1}$ rrl25630.@gmail.com \\ ${ }^{2}$ Dhishan. Dhammearatchi@cinec.edu
}

DOI: 10.29322/IJSRP.11.12.2021.p12059

http://dx.doi.org/10.29322/IJSRP.11.12.2021.p12059

\begin{abstract}
Mobile fitness applications are commonly used by people to keep their body health and fitness in good levels. These days, thousands of fitness applications can be downloaded from app stores. But these applications do not have the accuracy to be specific to everyone who is using the application. The purpose of this paper is to find ways to make fitness applications to be more specific to all users, increase their accuracy and discuss how to make a fitness application which can provide unique features to anyone who is using the application.
\end{abstract}

Keywords — fitness, fitness and health, mobile fitness applications, fitness apps.

\section{INTRODUCTION}

Health and fitness applications are applications that can be downloaded and used on any mobile device. These applications help their users to track their health, get fitness goals and receive instructions. Some of these can even connect and synchronize with wearable fitness trackers to track the user's health. According to IQVIA Institute [5], there are more than 318,000 health and fitness applications in all major Appstore, and $33 \%$ of the global population uses these health and fitness applications [8]. But only a minority of these applications have randomized controlled trials (RCTs) results and evidence regarding the application that have a good effect on their users' health [2]. This means most of the applications on the internet are failures or do not have reliable accuracy levels. The authors have discussed about a way to make a smart fitness coach application which will have distinctive features for each individual who uses the application. Also, the application should be able to provide

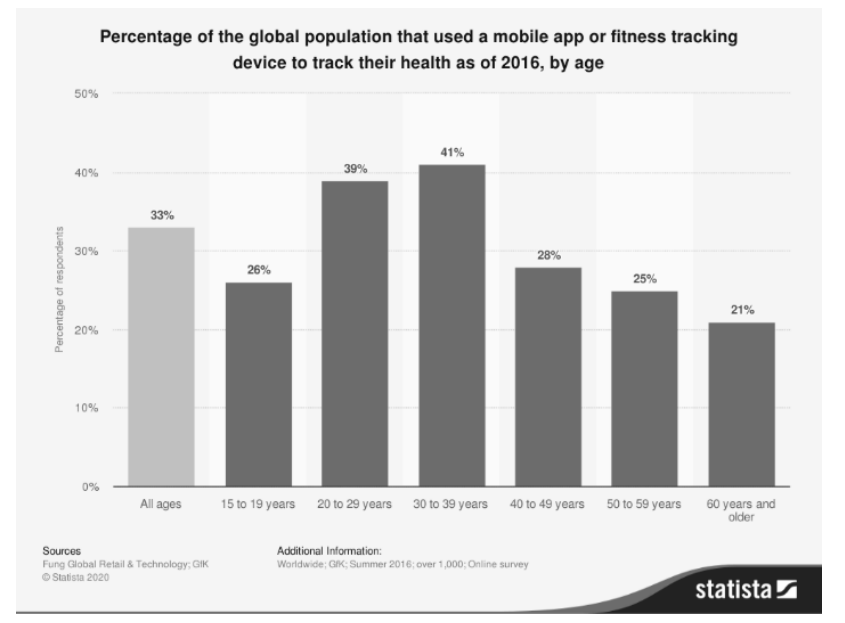

suggestions to the users on whether they need to improve their flexibility, strength, speed, or endurance.

Figure 1 : Percentage of the global population that used mobile fitness applications, by age (2016)

\section{Source:}

https://www.statista.com/statistics/742448/global-fitnesstracking-and-technology-by-age/

\section{LITERATURE REVIEW}

From the Stone Age onwards, humans invented new things and methods to make their work easier. Over time, new inventions and methods have made it possible for human beings to carry out their daily activities with ease and efficiency. With the introduction of ENIAC, the world's first computer, in 1946, man was able to take the work of all fields to a whole new dimension and find ways to make almost all tasks using computers much easier. This, however, had a somewhat detrimental effect on man's active life. With the advancement of information technology, work in many fields became automated or semi-automated. As a result, many people's work was limited to sitting in front of a computer and pressing a few buttons. With the introduction of computer games, children became more addicted to computer games than active sports such as football and cricket. Today, everyone from a small child to a middle-aged person uses mobile phones. Nowadays, in addition to making calls, you can order food, find your way and much more using your mobile phone. This is due to the fact that people are addicted to using their mobile phones for most of the day without doing any work. According to World Health Organization (WHO) [11], Non Communicable diseases(NCDs), such as raised blood pressure (to which $19 \%$ of global deaths are attributed), increased blood glucose (hyperglycemia), elevated blood lipids (hyperlipidemia) and obesity, are on the rise worldwide due to a lack of adequate physical activity and unhealthful diet. NCDs kill 41 million people each year which equivalent to $71 \%$ of global deaths. And physical inactivity kills about 1.6 million people a year. As a solution to physical inactivity, WHO released recommendation for physical activities [12]. WHO defines physical activity as "any bodily movement produced by skeletal muscles that requires energy expenditure - including activities undertaken while working, playing, carrying out household chores, travelling, and engaging in recreational pursuits". Exercises which is subcategory of physical activity can be used for maintaining the 
recommendations of physical activity of all ages. For an example, people can do yoga, jogging or other such exercises in order to maintain their body fitness. To do exercises correctly, people can hire personal instructors, go to yoga classes, or visit the gymnasium regularly. However, information technology itself has found a solution to this. That is, mobile fitness applications. With mobile fitness applications came to the health and fitness industry, health and fitness industry was digitized.

\section{RESEARCH QUESTIONS AND OBJECTIVES}

1. Is there are a way to improve the accuracy in fitness applications and if there is a way, how?

2. What kind of data should be gathered from users to do that?

\section{General Objectives}

1. Yes. User data collection can be used to improve the accuracy of fitness applications

2. To specify for each user, unique user data can be collected for each user.

\section{Specific Objectives}

1. Gathering unique data from each user could be used to improve applications' accuracy. With correct data collection, application can be more specific to their users.

2. The usage of the application, user's age, gender, height, weight. Collecting data will vary with usage of the application.

\section{HYPOTHESIS}

The idea is to gather the required data from the user, process the data in the most accurate way and give relevant instructions to the users. First, the user needs to consider if they are using the application for a normal lifestyle or for sports activities. After that, the application needs to collect data regarding the user's age, gender, height, weight. Collecting data will vary with usage of the application. For example, if the user is going to use the application for a normal lifestyle, the application should collect more data about the user's waist - hip ratio (Figure 2 is showing men's' and women's hip and waist)and other such factors. After getting the data from user, the application will provide simple tests to examine the user's flexibility, strength, and endurance. It also should change with usage of the application. The user must do the tests themselves and they should provide the test results to application. The application

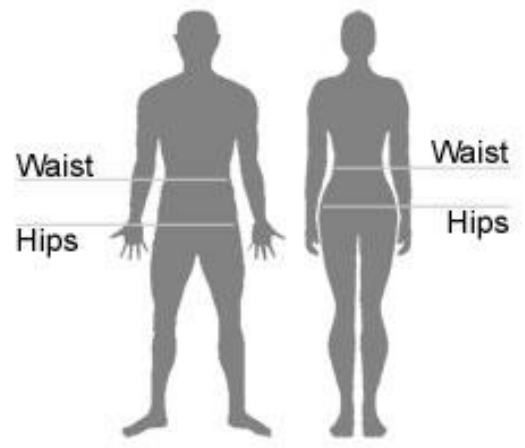

This publication is licensed under Creative Commons Attribution CC BY. http://dx.doi.org/10.29322/IJSRP.11.12.2021.p12059 processes the given results and then predicts whether the user needs to develop on flexibility, strength, or endurance.

\section{Figure 3 : waist and hip}

\section{A. Tests given to users}

To measure the user's fitness level, the application will provide various tests and the user should submit his or her test results to the application according to the given levels. The tests and levels should be change to normal lifestyle and sport activities. Also, application should provide video which include steps to do each test.

\section{IV.A.1 FLEXIBILITY TEST}

The test is known as sit and reach. To do this, the user needs to remove his or her shoes and sit on a flat surface, legs extended in front of the body, toes pointing up and feet slightly apart, with the soles of the feet against the base of the wall . Placing one hand on top of the other, the user must reach slowly forward. At the point of user's greatest reach, he or she needs to hold for a couple of seconds, and measure how far they have reached. [4]

\section{IV.A.2 STRENGTH TEST}

\section{IV.A.2.1 PUSH UPS}

do this

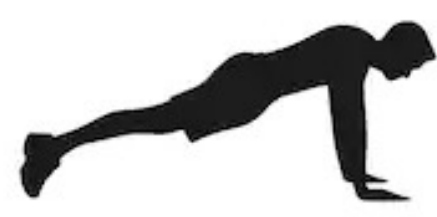
the user needs to get down on all fours, place their

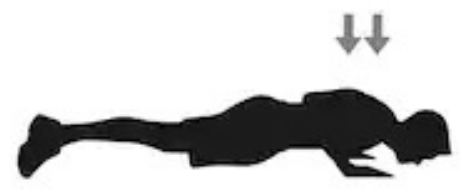

hands

slightly wider than their

shoulders, straighten the arms and legs and lower the body until his or her chest nearly touches the floor. Pause, then push themselves back up. The user must repeat these steps as many times as they can, and measure how many times they repeat the steps[4]. Figure 3 showing positions of standard push-up.

\section{(Source: Shutterstock.com)}

\section{Figure 2 : Standard Push-up}

\section{IV.A.2.2 SIT UPS}

To do this the user needs to lie down on his or her back, bend the legs and place the feet on the ground to stabilize the lower body, cross hands to opposite shoulders or place them behind the ears and without pulling the neck, curl the upper body all the way up towards to his or her knees. Exhale while 

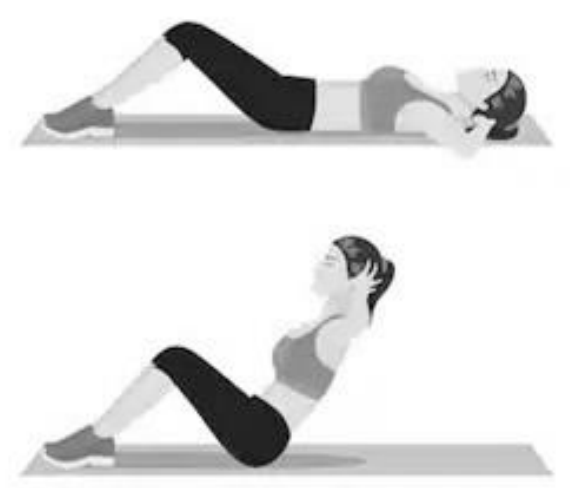

lifting. Slowly, lower down and return to the starting point. Inhale while lowering. Figure 3 showing positions of standard sit-up.

\section{Source: Shutterstock.com}

\section{IV.A.3 ENDURANCE TEST}

\section{Figure 5 : Standard Sit-up}

The test is called the beep test and is also known as the bleep test. The beep test is a multi-stage fitness test used to measure cardiovascular fitness and maximum oxygen uptake (VO2 max). The application should provide the beep test soundtrack to the user. To do this test, the user needs a flat surface which is suitable for running 20 meters and he or she should mark the $20 \mathrm{~m}$ distance with some markers. The user then needs to position themselves at one of the markers. After that, the user can start the beep test. He or she needs to run 20 meters to the opposite marker and get there before the next beep sound (each run is called as shuttle) and wait there until the beep sounds before running back to the marker. The user should repeat the process for each shuttle until they are unable to keep up with the beeps. User's final score is the last level and shuttle they completed before missing a beep [1] [4].

\section{Figure 4 : Beep/Bleep test}

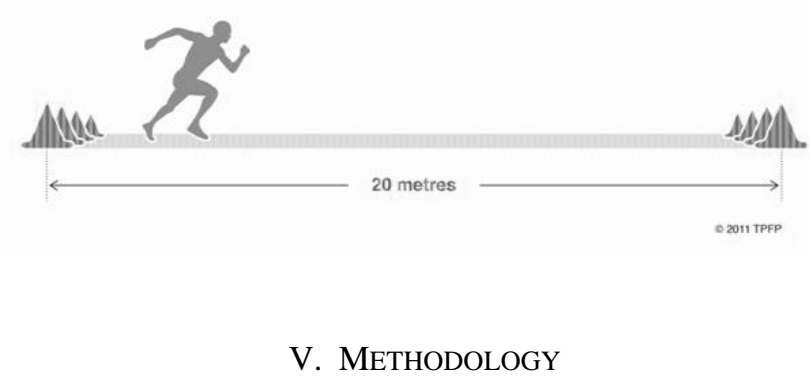

\section{A. Planning}

With the Health and Fitness app gaining a leading position in the field of fitness and healthcare, various fitness apps came to the forefront of app stores. In such a situation, it seems that mobile fitness applications need an accepted standard. And while in the standard, also fitness application should be needing an accuracy to be specific on their users.

\section{B. Requirement gathering and analysis}

The authors collect data from interviews with people who already using mobile fitness applications, fitness coaches and sport officers and sri lanka ministry of sports.

After collecting data in these ways, the authors were able to identify user expectations.

\section{Design}

The authors are expecting to design a mobile fitness application according to identified requirements.

\section{Implementation}

The application requires an interface to interact with the user and it requires database to store the gathered data from user. Flutter can be used to crate interfaces, and firebase uses as the database.

\section{E. Testing}

After creating the mobile application, the authors expect to give it to a randomly selected group of persons and test the research

\section{CONCLUSIONS}

In conclusion, fitness applications should be developed in such a way that they are more specific to their users. When releasing a fitness application to mobile app stores, it should have a standard and it should contain evidence regarding its effectiveness with its users.

\section{ACKNOWLEDGEMENT}

I would like to express my full gratitude to Mr.Dhishan Dhammearatchi and department of information technology for his primary encouragement and supervision of this research.

\section{REFERENCES}

[1] Beepfitness.com, "Help - Beep Fitness Test," Beepfitness.com, [Online]. Available: https://beepfitness.com/help.html. [Accessed 20 Augest 2020].

[2] O. Byambasuren, S. Sanders, E. Beller and P. Glasziou, "Prescribable mHealth apps identified from an overview of systematic reviews," npj Digital Medicine, vol. I, no. 1, 2018.

[3] W. Chiu and H. Cho, "The role of technology readiness in individuals' intention to use health and fitness applications: a comparison between users and non-users," Asia Pacific Journal of Marketing and Logistics, 2020.

[4] T. a. V. E. Commission, NATIONAL COMPETENCY STANDARD \& COMPETENCY BASED TRAINING CURRICULUM FOR Coach (Sports) NVQ Level 4, Tertiary and Vocational Education Commission, 2019.

[5] I. Institute, “The Growing Value of Digital Health,” IQVIA Institute, 2017. 
ISSN 2250-3153

[6] G. News, "There are thousands of health and fitness apps, and not much evidence they work: study," Global News, 2020. [Online]. Available: https://globalnews.ca/news/4215969/do-fitness-appswork/. [Accessed 20 August 2020].

[7] PCMAG, "The Best Fitness Apps for 2020," PCMAG, [Online]. Available: https://www.pcmag.com/news/the-best-fitness-apps-for2020. [Accessed 20 August 2020].

[8] Statista, "Percentage of people that used technology to track their fitness by age 2016 | Statista," Statista, [Online]. Available: https://www.statista.com/statistics/742448/global-fitness-trackingand-technology-by-age/. [Accessed 20 August 2020].

[9] A. Statistics, "Top categories on Google Play |AppBrain," AppBrain, [Online]. Available: https://www.appbrain.com/stats/android-marketapp-categories. [Accessed 20 August 2020].

[10] A. Tham, L. Kim, VictorySean, Y. Chen, K. Zheng and E. V. Eikey, "A content analysis of popular diet, fitness, and weight self-tracking mobile apps on Google Play," iSchools, 2020.

[11] Who.int, "Non communicable diseases," [Online]. Available: https://www.who.int/news-room/factsheets/detail/noncommunicable-diseases. [Accessed 25 August 2020].

[12] Who.int, "Physical activity," 2020. [Online]. Available: https://www.who.int/news-room/fact-sheets/detail/physical-activity. [Accessed 25 August 2020]. 